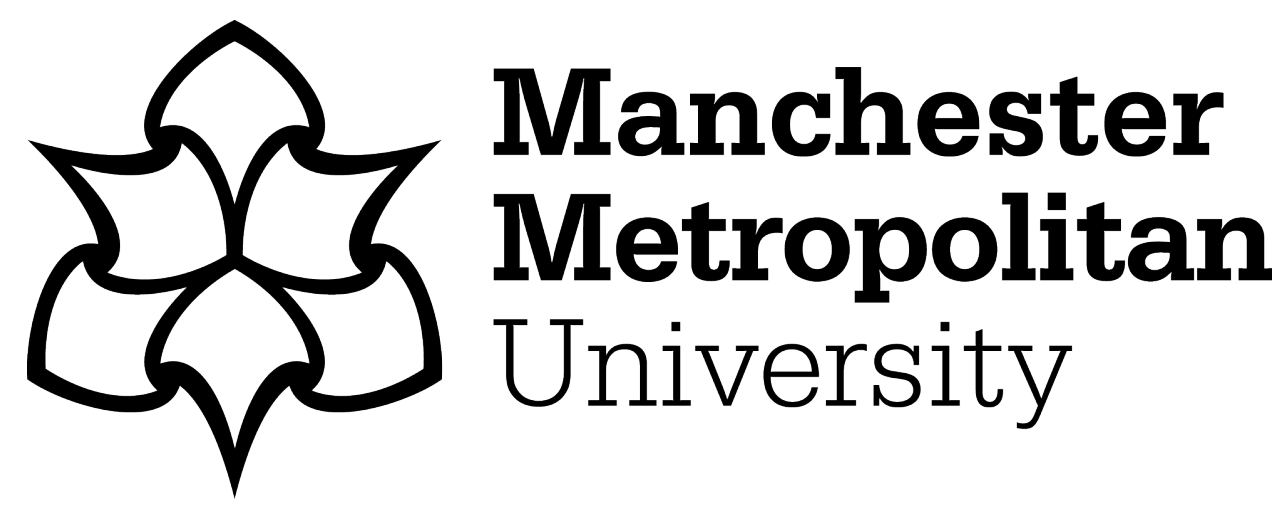

Francis, B, Harris, DA, Wallace, S ORCID logoORCID: https://orcid.org/00000001-6244-860X, Knight, RA and Soothill, K (2013) Sexual and General Offending Trajectories of Men Referred for Civil Commitment. Sexual Abuse: a journal of research and treatment, 26 (4). pp. 311-329. ISSN 1079-0632

Downloaded from: https://e-space.mmu.ac.uk/627637/

Version: Accepted Version

Publisher: Springer Verlag

DOI: https://doi.org/10.1177/1079063213492341

Please cite the published version 


\title{
Sexual and General Offending Trajectories of Men Referred for Civil Commitment
}

\section{Brian Francis', Danielle Arlanda Harris², Stephanie Wallace ${ }^{3}$, Raymond A. Knight ${ }^{4}$, and Keith Soothill ${ }^{3}$}

\begin{abstract}
Policies aimed at managing high-risk offenders, which include sex offenders, often assume they are a homogeneous population. These policies also tend to assume the pattern of offending is the same for all sex offenders, and is stable. This study challenges these assumptions by examining the life course offending trajectories of 780 convicted adult male sexual offenders. The men were referred to the Massachusetts Treatment Center for civil commitment between 1959 and 1984. The changing number of both sexual and any offenses were examined by age using GroupBased Trajectory Modeling. We identified a four-trajectory model for all offending and a four-trajectory model for sexual offending. The identified groups varied in several offending patterns including criminal onset, length of criminal careers, age of peak offending, and time of entry into the treatment center. Late adult onset of sex offending was found to be associated with child molestation, whereas early-onset trajectories were associated with rape. Implications for future research and policy are discussed.
\end{abstract}

\section{Keywords}

sexual offending, trajectory analysis, criminal career, child molestation, adult onset, age-crime curve

\footnotetext{
'Department of Mathematics and Statistics, Lancaster University, UK 2Department of Justice Studies, San Jose State University, CA, USA ${ }^{3}$ Department of Mathematics and Statistics, Lancaster University, UK ${ }^{4}$ Department of Psychology, Brandeis University, MA, USA
}

\section{Corresponding Author:}

Danielle Arlanda Harris, Department of Justice Studies, San Jose State University, One Washington Square, San Jose, CA $95192-0050$, USA.

Email: danielle.harris@sjsu.edu 
In the Western world, perceptions about sex crime have changed over the past 30 years. In brief, a new way of looking at sex offending has been developed. There are various ways of summarizing these changes, but at least three crucial features can be identified. First, although three decades ago sex offending was not considered to be a pervasive crime, nowadays it is. Second, concomitant with the women's movement in the late 1960s and early 1970s embracing the crime of rape as a focus of public concern has changed. This helped to develop an appreciation and understanding of the immense harm and trauma caused by sexual violence. The gradual discovery of child sexual abuse that began in the 1960s accelerated in the 1980s with the recognition of child sex abuse occurring in the family. Since the 1990s the focus in the United Kingdom and the United States has shifted from the family to "stranger-danger" with a series of highprofile cases of sexual murders involving children, vividly reported in newspapers and in television coverage (Ewing, 2011; Harris, Smallbone, Dennison, \& Knight, 2009b; Lieb, Quinsey, \& Berliner, 1998; Simon, 1997). There is currently considerable public interest in sex offending. Third, the official response to sex offending has changed, largely in response to this major shift in public interest. Sex offender recidivism has captured the attention of politicians, resulting in provisions such as notification and registration schemes to counter the supposed threats from known sex offenders (Laws \& Ward, 2011; Willis, Levenson, \& Ward, 2010). Similarly, the investment in risk assessment procedures has increased (Laws \& Ward, 2011). Heightened professional interest has also produced other shifts. Although previously there was a general pessimism about the effect of treatment, guarded optimism about the success of certain treatments for some sex offenders has emerged (e.g., Alexander, 1999; Hanson, Bourgon, Helmus, \& Hodgson, 2009; Lösel \& Schmucker, 2005). In fact, the study of sex offender recidivism has made some significant advances (Soothill, 2010), but there are still some important conceptual and empirical issues about sex offending to confront.

The study of sexual offenders in general and their sex offending in particular has had a curious history. A kind of "sexual apartheid" has separated such study from the mainstream of social science. It is essential that sex-offending research be more firmly integrated into the framework of mainstream criminal careers research and developmental criminology and psychopathology. In some respects this has been accomplished with some unexpected results.

The use of the term "sexual offender" suggests that they are a homogeneous and coherent group but this belief can be misleading. In fact, there has been much discussion about whether sex offenders are "specialists" (that is, specializing in sex offending) or "generalists" (that is, involved in a wide variety of offending in addition to sex offending; Harris, 2008; Harris, Mazerolle, \& Knight, 2009a; Harris, Smallbone et al., 2009b). Elsewhere (Soothill, Francis, Sanderson, \& Ackerley, 2000), we have argued that the dichotomy can be misleading and particular offenders can be both generalists and specialists. Sullivan, McGloin, Pratt, and Piquero (2006) and McGloin, Sullivan, and Piquero (2009) have usefully developed this theme by introducing the notion of short-term specialization. There is some modest support for the idea from their evidence, but the notion has not been considered specifically for sex offending. 
Although the sophisticated analysis of offending trajectories is a burgeoning field, little work has thus far been done on sex offending over the life course. There have been two approaches. First, a number of studies have employed trajectory analysis to examine the recidivism patterns of sex offenders (Jennings, Zgoba, \& Tewksbury, 2012; Tewksbury \& Jennings, 2010; Tewksbury, Jennings, \& Zgoba, 2012). These studies have used follow-up periods of 5 and 8 years following release from prison and have not examined offending prior to incarceration. Rather than examine changes in offending over age, these studies have examined changes by years since release. The trajectories found therefore contain a mix of offenders of different ages at each time point.

Second, a smaller number of studies have looked at offending trajectories of sexual offenders over the life course where the time axis is the age of the offender and not the number of years since release. Lussier, Tzoumakis, Cale, and Amirault (2010) examined the general offending (i.e., all types of offending) trajectories up to age 35 of sexual offenders who were incarcerated in a maximum-security institution in Quebec for more than 2 years. They used four periods of 6 years (12-17, 18-23, 24-29, and 30-35) and assessed criminal charges from official records. They found four general offending trajectories that echo Moffitt's (1993) work. So, for instance, they found that high-rate chronics had the earliest age of onset, but there was no difference in the total number of sexual crimes committed across the four groups. These are clues that there is another story to tell. They found, for instance, that the "very low-rate offenders" group began offending relatively late (in adulthood, approaching the mid-40s) and were more likely to include child molesters than rapists. Lussier and Davies (2011) extended the work of Lussier et al. (2010) by looking more specifically at sexual offending trajectories, as well as sexual and violent offending trajectories for the same sample of convicted sex offenders in the province of Quebec, Canada. Using 6-year aggregated data on counts of charges, they identified two sexual offending trajectories up to age 35: a very low offending group and a high-rate increasers group. Most recently, Freiburger, Marcum, Iannacchione, and Higgins (2012) investigated 500 sex offenders arrested between 1993 and 2007 in Virginia. The authors collapsed yearly count data of sexual offense arrests between the ages of 19 and 33 into binary indicators. They found three distinct sexual arrest trajectories: one peaking at age 25 , one peaking around age 30, and the final group peaking at age 32 .

We focus on the second group of studies, and examine the three pieces of research which look at life course offending of sexual offenders. Lussier and Davies's (2011) and Lussier et al.'s (2010) work represents an impressive first step in the quest to understand sexual offending life course trajectories, but there are methodological issues that limit its contribution. Most notably, these include the relatively young (up to age 35) and small sample $(n=393)$. Freiburger et al.'s (2012) analysis was similarly limited, including ages 19 through 33, and thus also excluding juvenile as well as later sexual offending. In addition, the loss of information caused by collapsing count data into binary indicators means that the trajectories in this study do not measure true frequency of arrest.

The benefits of long-term follow-ups beyond age 35 are made clear in other studies. Hanson (2002), for example, reported on the multimodal age-crime curve sometimes 
observed for sex offenders with one peak between 16 and 25 years and another between 35 and 45 years. Similarly, Smallbone, Marshall, \& Wortley (2008), identified an agecrime curve which is distinctly bimodal. They found a peak in mid-adolescence, but also a second in the mid to late 30s. Both Hanson (2002) and Smallbone et al. (2008) have speculated that these peaks coincide with differential opportunity structures during each period of a person's life. Such situations might include sexual exploration and dating during adolescence and marital-related difficulties or access to children later in life. Francis, Hargreaves, and Soothill (2014) suggest that a proportion of those offending after age 40 do indeed start offending very late in life. The suggestion is that the second group consists of those older males with increased opportunities for access to children from relatives and friends. The discovery of such a late offending group has not been possible in the three lifetime sexual offending studies discussed earlier.

The present study focuses on both "any offending" (sexual and nonsexual combined) and "sexual offending" trajectories of 780 men up to their referral for civil commitment at the Massachusetts Treatment Center (MTC; in Bridgewater, Massachusetts). There is no age constraint as referral can occur at any age up to age 90. The sample is selectively composed in the direction of sexual dangerousness and oversamples serious, violent, repeat sexual offenders. We return to this point in the discussion. Our study's focus on those referred for civil commitment is important for at least two reasons. First, these are the sex offenders who raise much public anxiety, and they are the individuals at whom many current pieces of legislation have been targeted. Second, it is crucial to understand whether these offenders share similar offending trajectories or, indeed, whether sexually specific offending trajectories can be identified. That latter point is the main focus of the present study. Our research questions are below:

1. Can distinct trajectories of "any offending" over the life course (up to referral) be identified among those men observed at the MTC? This extends previous work on general life course trajectories focusing on the complete age span using criminal histories up to referral.

2. Are there distinct sexual offending trajectories over the entire life course?

3. If distinct groups can be identified, then what are the characteristics of the groups and how are the "any offending" and "sexual offending" groups related?

\section{Method}

\section{Participants}

The sample comprised two subsamples of offenders observed at the MTC between 1959 and 1984 and for whom detailed criminal histories were available. The first group included consecutive admissions of 489 men who were observed, determined to be "sexually dangerous," and committed for treatment. The remaining 291 men were an equal combination of a random and matched (to the committed on marital status, age, and prior offense frequency) selection of offenders who were observed, assessed, 
and released (to either the community or back to prison to serve their remaining sentence). The median age of referral was 27 years with a range of 14 to 70 years.

It is reasonable to assume that this series contained a potentially more serious set of offenders than generic samples of sex offenders not referred for civil commitment. This conjecture was supported by the consistently higher actuarial scores than generic prison sex offender samples found in a subset of these offenders (Knight \& Thornton, 2007).

\section{Procedure}

The officially recorded criminal history (charges) for each member of the series up to the time of referral were extracted previously (Harris, 2008) with the earliest charge being in 1912. The charges were classified into 20 offense types $^{1}$ that were further collapsed into four categories: sexual, nonsexual violence, property, and miscellaneous. Everyone in the sample had at least one contact sexual offense against an adult or a child. Cases that included charges for acts that are no longer illegal (e.g., adultery, homosexuality) were excluded from the analysis. The charge date was recorded for each offense, and if not available the best approximation of that date was used.

\section{Analyses}

The analyses for this study used Group-Based Trajectory Modeling (GBTM) up to referral on (a) any offending and (b) sexual offending only. GBTM is a statistical application which assumes "a population is composed of a mixture of distinct groups defined by their developmental trajectories" (Nagin \& Odgers, 2010, p. 115). The counts of charges were aggregated into 5-year windows (9-13, 14-18, 19-23, etc.) up to the age of referral for both "any offending" (that is, all types of offending including sexual offending) and "sexual offending only." An exposure variable for each window was also calculated giving the number of years at risk within the time period. For most observations this was 5 years, but for the window containing the referral, the exposure was calculated to be the time in years from the start of the window to referral. Counts in windows over the age of referral were set to missing. We also investigated using 1 year rather than 5-year windows to investigate the stability of the choice of 5-year windows, but entropy measures for the best solutions were low compared to the 5-year window analysis. The aggregation of counts into 5 -year windows additionally appeared to improve the stability of the analysis particularly in the sexual offending trajectories, where offending can remain undetected for a number of years, followed by a spike of charged offense counts which represent the offending over the undetected period.

The model was fitted in Latent Gold (Vermunt \& Magidson, 2005) assuming an underlying negative binomial distribution with a group-independent dispersion parameter to account for over dispersion in the number of offenses. We accounted for variation in trajectory shape over age by fitting separate cubic curves for each trajectory.

It is important to note that individuals contribute data only up to the time of referral. With varying referral ages across the sample, the data were therefore unbalanced. 
Software such as Latent Gold can deal with such unbalanced data by treating the unobserved observations after referral as missing. The analysis thus uses Full Information Maximum Likelihood (FIML) to estimate the trajectories (Collins \& Lanza, 2010) and therefore assumes that missing values are missing at random.

There were two active covariates included in the analysis that modeled the probability of trajectory group membership: (a) referral status (committed/observed); and (b) sexual offender classification (rapist, child molester, incest only, mixed, and noncontact).

For each type of offending, a sequence of models was fitted with increasing numbers of trajectories.

We determined the number of trajectories by a combination of approaches. It is common in criminological applications for the Bayes Information Criterion (BIC) to be used to determine the number of groups. Simulation studies by Brame, Nagin, and Wasserman (2006) have shown that BIC performs better than the Akaike Information Criterion (AIC) for a wide variety of problems. Nagin (2005) suggests, however, that this be used with caution, stating that "how best to determine the number of groups comprising a finite mixture model is not a settled issue." The $\mathrm{AIC}^{2}$ has also been found useful in providing guidance for choosing the number of trajectory groups, and there is evidence that it outperforms other information criteria, including BIC in latent class problems (Dias, 2006).

Nagin (2005) also points out that in some applications, BIC can fail to cleanly identify a preferred number of groups. He suggests that "more subjective criteria based on domain knowledge and the objectives of the analysis must be used to select the number of groups to include in the model" (Nagin, 2005, p. 74), and that model selection needs to balance the competing objectives of model parsimony and "capturing the distinctive features of the data" (p. 75). We therefore examined both BIC and AIC3 to guide the number of chosen groups, but also examined in detail the resulting trajectories so that models with trajectories which appeared to be similar in nature were simplified. Finally, the entropy of the model was also examined, with values closer to one indicating posterior probabilities of the best group membership closer to one.

\section{Results}

\section{Any Offending Trajectories}

The first analysis considered all of the charges (for sexual and nonsexual offenses) for each participant up to the time of referral. Table 1 displays the BIC, AIC 3 and entropy scores for the one to five group solutions, taking the best out of 1,000 different starting values. We concluded that a four-group solution provided the best model. This had the lowest value of both BIC and AIC3. The four-group model is shown in Figure 1, and the groups are summarized below.

The overall picture in Figure 1 depicts two main trajectories that essentially represent early-onset offending limited to early adulthood (Groups $1 \& 4$ ) and later onset persistence (Groups $2 \& 3$ ). The main distinction between each pair is frequency of 
Table I. Determination of Number of Trajectory Groups for Any Offending.

\begin{tabular}{lllc}
\hline Number of Groups & BIC & AIC3 & Entropy \\
\hline 1 & $16,319.93$ & $16,301.54$ & 1 \\
2 & $15,863.8$ & $15,812.3$ & 0.6895 \\
3 & $15,750.03$ & $15,665.43$ & 0.6306 \\
4 & $15,741.66$ & $15,623.95$ & 0.6058 \\
5 & $15,788.92$ & $15,638.11$ & 0.5987 \\
\hline
\end{tabular}

Note: $\mathrm{BIC}=$ Bayes Information Criterion. $\mathrm{AIC}=$ Akaike Information Criterion.

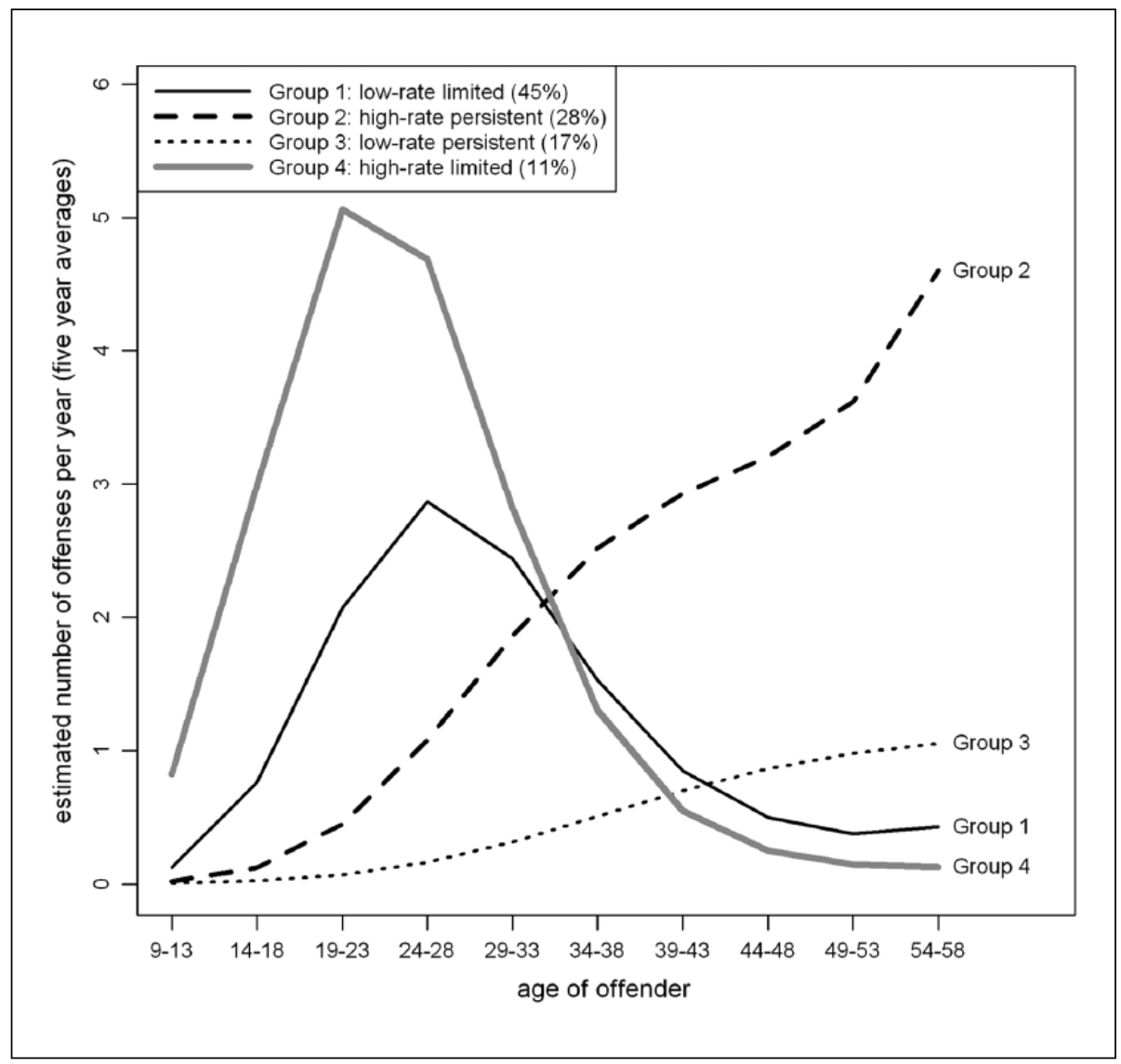

Figure I. Four-Group Trajectories of Any Offending.

offending. We label the groups as follows: "low-rate limited" (Group 1; 45\% of sample); "high-rate limited" (Group 4; 11\% of sample); "high-rate persistent" (Group 2; $28 \%$ of sample); and "low-rate persistent" (Group 3; 17\% of sample). 
Table 2. Criminal History Summaries and Covariate Effects For Any Offending Trajectories.

\begin{tabular}{|c|c|c|c|c|}
\hline & $\begin{array}{c}\text { Low-rate } \\
\text { Limited } \\
\text { (Group I) } \\
45 \%\end{array}$ & $\begin{array}{c}\text { High-rate } \\
\text { Persistent } \\
\text { (Group 2) } \\
28 \%\end{array}$ & $\begin{array}{c}\text { Low-rate } \\
\text { Persistent } \\
\text { (Group 3) } \\
\text { I7\% }\end{array}$ & $\begin{array}{c}\text { High-rate } \\
\text { Limited } \\
\text { (Group 4) } \\
\text { । I\% }\end{array}$ \\
\hline Mean age of onset & 15.9 & 21.1 & 28.7 & 13.1 \\
\hline Mean age of referral & 25.3 & 31.0 & 42.0 & 20.9 \\
\hline $\begin{array}{l}\text { Mean time from onset to } \\
\text { referral }\end{array}$ & 9.4 & 9.9 & 13.3 & 7.8 \\
\hline $\begin{array}{l}\text { Age window of peak } \\
\text { offending }\end{array}$ & $19-23$ & $54-58$ & $54-58$ & $24-28$ \\
\hline $\begin{array}{l}\text { Mean rate of sexual offending } \\
\text { (charges/year) }\end{array}$ & 0.83 & 1.88 & 0.85 & 0.85 \\
\hline \multicolumn{5}{|l|}{ Offender classification } \\
\hline Rapist & $43.7 \%$ & $24.2 \%$ & $9.5 \%$ & $78.3 \%$ \\
\hline Child molester & $35.2 \%$ & $56.2 \%$ & $55.1 \%$ & $12.3 \%$ \\
\hline Incest & $1.3 \%$ & $1.1 \%$ & $18.0 \%$ & $0.0 \%$ \\
\hline Mixed/noncontact/other & $19.8 \%$ & $18.5 \%$ & $17.4 \%$ & $9.5 \%$ \\
\hline \multicolumn{5}{|l|}{ Referral status } \\
\hline Committed & $69.7 \%$ & $53.0 \%$ & $43.5 \%$ & $83.4 \%$ \\
\hline Observed & $30.3 \%$ & $47.0 \%$ & $56.5 \%$ & $16.6 \%$ \\
\hline
\end{tabular}

Table 2 shows the differences between the four trajectory groups on a collection of summary criminal career variables: mean age of onset, mean age at referral, mean time from onset to referral, and age of peak offending. The low-rate limiteds (Group 1) and the high-rate limiteds (Group 4) both followed the expected pattern of the traditional age-crime curve with relatively early-onset ages (15.9 and 13.1 years, respectively), early periods of peak offending, and gradual deescalation. In contrast, the high-rate persistents (Group 2) and low-rate persistents (Group 3) followed a rather different offending pattern marked by considerably later onset (21.1 and 28.7 years, respectively) and gradual escalation.

Table 2 also shows the differences between the four trajectory groups on the rate of sexual offending over their offending career until referral, type of sex offender, and referral status. The rate of sexual offending from criminal onset to referral was similar at just under one charge per year for three of the groups (Groups 1, 3, and 4). The exception was the high-rate persistent group (Group 2), with a sexual offending rate of double that of the other groups with 1.87 charges per year. The two limited groups (Groups 1 and 4) mostly consisted of rapists with almost all low-rate limiteds (Group 1; $78.3 \%$ ) committing sexual offenses against adults. In contrast, child molesters were overrepresented in both late-onset groups: the high-rate persistents (Group 2; 56.2\%) and low-rate persistents (Group 3; 55.1\%). Referral status also differentiated between groups with low-rate limiteds (Group 1; 70.7\%) and high-rate limiteds (Group 4; $83.1 \%$ ) both being more likely than their later onset counterparts to be committed at 
Table 3. Determination of Number of Trajectory Groups for Sexual Offending.

\begin{tabular}{lccc}
\hline Number of Groups & BIC & AIC3 & Entropy \\
\hline 1 & $9,645.63$ & $9,627.33$ & 1 \\
2 & $9,482.96$ & $9,431.73$ & 0.53 \\
3 & $9,444.26$ & $9,360.09$ & 0.552 \\
4 & $9,476.77$ & $9,359.67$ & 0.565 \\
5 & $9,523.50$ & $9,373.47$ & 0.561 \\
\hline
\end{tabular}

Note: $\mathrm{BIC}=$ Bayes Information Criterion. $\mathrm{AIC}=$ Akaike Information Criterion.

the MTC. Both offender classification (rapist/child molester) and referral status (committed/observed) were significant $(p<.001)$.

We also considered the average journey from age at first criminal charge to age at the time of referral. Low-rate persistents had the oldest average age at onset and the longest journey of 13.3 years before being referred, whereas the other three groups (low-rate limiteds, high-rate persistents, and high-rate limiteds) had similar journey times of 9.4 years, 9.9 years, and 7.8 years, respectively.

\section{Sexual Offending Trajectories}

Table 3 shows the BIC, AIC3, and entropy values for one to five groups when sexual offenses alone are considered. Here the BIC has a minimum at three groups, whereas the AIC3 has a minimum at four groups. As the four-group solution has a slightly higher entropy value, and the four-group solution identified four distinct trajectory shapes, we chose the four-group solution over the three-group solution.

The results in Figure 2 show the four distinct sexual offending trajectories identified by the statistical analysis. When the summary criminal career variables are considered (Table 4), the differences between the trajectory groups are even more revealing than the analysis for the trajectories of any offending. Overall, sexual offending began considerably later than nonsexual offending and three of the four groups exhibited some decrease in frequency or desistance with age. "Low-rate persistents" (Group 1) began offending on average in their late teens (18.3 years) and accounted for the largest proportion (56\%) of the sample. On average they offended less than once a year, peaking in their early $30 \mathrm{~s}$. The next group contained a quarter of the sample (24\%) and was classified as "high-rate limiteds" (Group 2). They had the earliest age of onset (15.2 years), peaking at more than two offenses a year in their mid to late 20s. The offending pattern of the high-rate limiteds (Group 2) was most consistent with the age-crime curve observed in general offending. They were especially identifiable by the steep decline in the frequency of their offending in their $50 \mathrm{~s}$.

The "high-rate accelerators" (Group 3) accounted for $12 \%$ of the sample. Their sexual offending on average began in the mid-20s (25.2 years) and increased steeply, reaching a peak of two and a half offenses per year in their mid-40s. The last group 


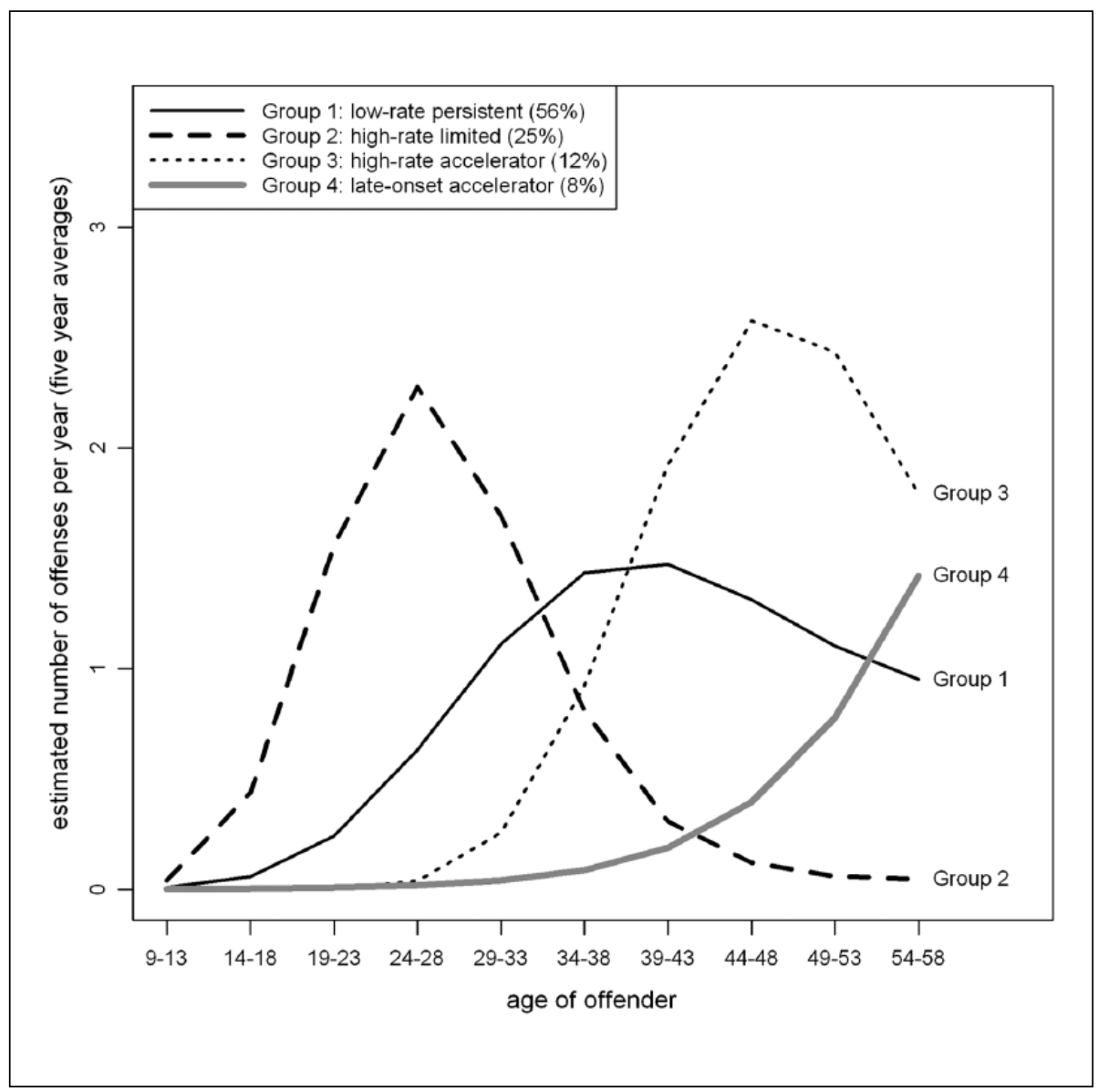

Figure 2. Four Group Trajectories of Sexual Offending.

"late-onset accelerators" (Group 4) consisted of only $8 \%$ of the sample and followed an especially distinct trajectory (lasting on average 20 years). Their sexual offending began the latest of all groups (27.8 years) and did not peak until their mid-50s.

The results of the covariate effects on the sexual offending trajectories are also contained in Table 4. As before, referral status $(p<.001)$ and sexual offender classification $(p=.004)$ in the groups of sexual offending trajectories, were highly significant. Certainly, there are observable differences in the lower half of Table 2 that help to clarify the nature of group differences. A crucial difference is that whereas the majority of high-rate limiteds (Group 2) were rapists, child molesters accounted for close to half of the remaining three groups. Incest offenders were present almost exclusively in the high-rate accelerator group (Group 3). Owing to their younger ages, the first three groups were more likely to be identified by studies that follow criminal careers up to 
Table 4. Criminal History Summaries and Covariate Effects for Sexual Offending Trajectories.

\begin{tabular}{lcccc}
\hline & $\begin{array}{c}\text { Low-rate } \\
\text { Persistent } \\
(\text { Group } 1) \\
56 \%\end{array}$ & $\begin{array}{c}\text { High-rate } \\
\text { Limited } \\
(\text { Group } 2) \\
25 \%\end{array}$ & $\begin{array}{c}\text { High-rate } \\
\text { Accelerator } \\
(\text { Group } 3) \\
12 \%\end{array}$ & $\begin{array}{c}\text { Late-onset } \\
\text { Accelerator } \\
(\text { Group 4) } \\
8 \%\end{array}$ \\
\hline Mean age of onset & 18.3 & 15.2 & 25.2 & 27.8 \\
Mean age of referral & 28.1 & 21.7 & 36.7 & 47.8 \\
Mean time from onset to referral & 9.8 & 6.5 & 11.5 & 20.0 \\
Age window of peak offending & $39-43$ & $24-28$ & $44-48$ & $54-58$ \\
Offender classification & & & & \\
$\quad$ Rapist & $39.1 \%$ & $49.7 \%$ & $9.0 \%$ & $7.4 \%$ \\
$\quad$ Child molester & $43.0 \%$ & $31.1 \%$ & $52.1 \%$ & $57.8 \%$ \\
$\quad$ Incest & $0.6 \%$ & $0.1 \%$ & $28.0 \%$ & $3.7 \%$ \\
$\quad$ Mixed/noncontact/other & $17.3 \%$ & $19.0 \%$ & $10.9 \%$ & $31.2 \%$ \\
Referral status & & & & \\
$\quad$ Committed & $57.9 \%$ & $92.2 \%$ & $30.6 \%$ & $53.7 \%$ \\
$\quad$ Observed & $42.1 \%$ & $7.8 \%$ & $69.4 \%$ & $46.3 \%$ \\
\hline
\end{tabular}

the offenders' mid-30s. This has contributed to the misleading perception that there is only one type of child molester (high-rate accelerators, in the present sample). Whereas high-rate accelerators (Group 3) are mostly child molesters with a relatively late average age of onset (25.2 years), one of the contributions of this study is the identification of an even later onset group (Group 4). The majority of offenders in each of this last group were involved in offenses against children.

Although the variables in the analysis were comparatively few, they usefully discriminated between the groups. The majority of the high-rate limiteds $(95.2 \%)$, low-rate persistents (57.9\%), and the late-onset accelerators $(53.9 \%)$ were committed for treatment rather than simply observed and returned to prison. In contrast, a much lower proportion of the high-rate accelerator group was committed for treatment $(30.6 \%)$.

Relationship Between the "Any Offending" Groups and the "Sexual Offending" Groups. We also examined the relationship between the four sexual offending trajectories and the four "any offending" trajectories. Table 5 shows the probability of belonging to each of the four "any offending" trajectories given membership of each of the sexual offending trajectories (and probabilities greater than 0.25 are highlighted). In general, we notice a strong association in this table between "sexual offending" and "any offending" group membership. Those in the high-rate limited sexual trajectory group (Group 2) are unlikely to belong to either of the two "any offending" persistent groups. In contrast, those with later sexual offending onset and peaking later (sexual offending Groups 3 and 4) are very likely to belong to the low or high-rate persistent groups. The low-rate, persistent, sexual offending group (Group 1) has a spread over all the "any offending" groups in a similar proportion to the overall sample. 
Table 5. Any Offending Group Membership Probabilities Conditional on Sexual Offending Group Membership.

\begin{tabular}{lccccc}
\hline & \multicolumn{5}{c}{ Any Offending Group } \\
\cline { 2 - 6 } $\begin{array}{l}\text { Sexual Offending } \\
\text { Group }\end{array}$ & $\begin{array}{c}\text { Low-Rate } \\
\text { Limited } \\
\text { (Group I) 45\% }\end{array}$ & $\begin{array}{c}\text { High-Rate } \\
\text { Persistent } \\
\text { (Group 2) 28\% }\end{array}$ & $\begin{array}{c}\text { Low-Rate } \\
\text { Persistent } \\
\text { (Group 3) 17\% }\end{array}$ & $\begin{array}{c}\text { High-Rate } \\
\text { Limited } \\
\text { (Group 4) II\% }\end{array}$ & Total \\
\hline $\begin{array}{l}\text { Low-rate } \\
\text { persistent } \\
\text { (Group 1-56\%) }\end{array}$ & $0.493 *$ & 0.349 & 0.085 & 0.073 & 1.000 \\
$\begin{array}{l}\text { High-rate limited } \\
\text { (Group 2-25\%) }\end{array}$ & 0.639 & 0.094 & 0.011 & 0.256 & 1.000 \\
$\begin{array}{c}\text { High-rate } \\
\text { accelerator } \\
\text { (Group 3-12\%) }\end{array}$ & 0.169 & 0.305 & 0.519 & 0.008 & 1.000 \\
$\begin{array}{c}\text { Late-onset } \\
\text { accelerator } \\
\text { (Group 4-8\%) }\end{array}$ & 0.130 & 0.176 & 0.691 & 0.004 & 1.000 \\
\hline
\end{tabular}

Note: *Probabilities over 0.25 are highlighted.

\section{Discussion}

Systematic longitudinal studies tend to be limited by the length of their follow-ups. The series underpinning Moffitt's (1993) work was originally up to age 26 (and subsequently, to age 32). Most parallel analyses have been similarly limited to an exposure of the samples only up to ages in the mid-30s. In contrast, Sampson and Laub's $(1993,2003)$ reanalysis of the Gluecks' data has identified a lifetime exposure (following individuals up to age 70). Further, Farrington's work on the Cambridge Study in Delinquent Development has followed individuals until age 50 (Farrington et al., 2006). To date, this length of exposure has not been possible in the follow-up of any large-scale investigations of the criminal history of sex offenders.

In this study we have applied the increasingly popular use of trajectory modeling to the area of sexual offending. Building on recent work, this study went beyond previous analyses in at least two ways. First, because no age constraint was imposed on those referred to the MTC, there was an opportunity for identifying patterns among much older offenders, and over much longer periods of time. Second, perhaps more importantly, this study has analyzed trajectories of both sexual and any (sexual and nonsexual) offending.

The existence of very late-onset groups has been controversial. Moffitt (1993) originally proposed two distinct categories of antisocial behavior and offending: life course persistent offenders on the one hand and adolescent-limited offenders on the other. The first type referred to offenders who had an early onset and continued offending throughout their life. In contrast, the adolescent-limited group consisted of those whose involvement in offending increased rapidly in early adolescence and 
then declined rapidly after a peak of activity at about 18 years. For the second group, offending occurred primarily during adolescence (Moffitt, 1993).

More recent examinations of her data have raised the possibility of additional groups. Most notably, a group of offenders who were found to commit crime intermittently throughout childhood and adulthood became known as "low level chronics" (Moffitt, 2006). Although they had previously been identified as a recovery group, it was subsequently concluded, through both official and self-report records, that their offending actually continued, as they got older. The case for "late bloomers" or adult onset offenders has also been proposed (Bushway, Thornberry, \& Krohn, 2003; Eggleston \& Laub, 2002) but Moffitt (2006) has maintained that this group is likely an artifact of studies that have drawn from official statistics exclusively (McGee \& Farrington, 2010). Moffitt (2006) has since argued that the observation of people who are first apprehended for offenses after age 18 does not threaten her original taxonomy.

Understanding the Four Trajectories For Any Offending. Although there is scope for comparing this four-group solution with various other series, for clarity we first limit the comparison of these results to Moffitt's (1993) study, which largely opened up the current debates about offender typologies. Second, we compare our results with those of Lussier et al.'s (2010) recent work, which focused on a series more akin to the sample in the present study.

Whereas Moffitt originally analyzed a birth cohort up to the age of 26 years who were from Dunedin, New Zealand, Lussier et al. (2010) focused on the general offending history up to age 35 of sexual offenders aged 36 or more who had been incarcerated in a maximum-security institution in Quebec for more than 2 years. Our own series comes from the MTC in the United States. With such very different contexts and countries, it would perhaps be, prima facie, quite remarkable if these three series had much in common. One can, however, fashion an overriding theoretical context in which similarities across these different samples could emerge.

If one argues that Moffitt's schema constitutes a general typology of offenders, one might expect Lussier et al.'s (2010) and the present series to be subsets of Moffitt's general offending taxonomy. In other words they are unlikely to have similar profiles but to have some similarities. Of course, if sex offenders are a completely distinct set of offenders from other offenders, such a relation with nonsexual offending would not be expected. A growing body of literature has, however, described considerable similarities between sexual offenders and general offenders. Many studies to date conclude that the majority of sexual offenders do not restrict their criminal activities to sexual offenses (Harris, 2008; Harris, Mazerolle et al., 2009a; Harris, Smallbone et al., 2009b; Lussier, 2005; Miethe, Olson, \& Mitchell, 2006; Soothill et al., 2000; Weinrott \& Saylor, 1991; Williams \& Arnold, 2002; Zimring, Piquero, \& Jennings, 2007). Even accounting for the bias inherent in clinical samples, a broad trend of versatility is maintained across studies. Further, although the differences between findings from official statistics and from self-reported responses are acknowledged, the ultimate message remains that those offenders who specialize in sexual offending are in the minority (Zimring et al., 2007). 
Our view is that there are two groups in Lussier et al.'s (2010) study and the present series that are reminiscent of two groups in Moffitt's study. Our high-rate limiteds resemble Moffitt's adolescent-limiteds and our low-rate persistents reflect Moffitt's life course persistents. The later onset groups that emerged in the present study (e.g., high-rate persistents) were not possible in Moffitt's original analysis because of that study's age constraints. One explanation of this finding might be that sexual offenders are different from the general population of offenders in having subsets of offenders with much later age onsets. This hypothesis cannot be fully tested until we have the evidence from other longitudinal studies of offenders that follow offenders to much older ages. That older onset offenders are limited to sexual offending seems unlikely. McGee and Farrington (2010) for example, recently examined the true prevalence of adult onset offending in the Cambridge Study in Delinquent Development. They concluded that although $46.2 \%$ of the total number of sexual offenses recorded were committed by late bloomers, adult onset offenders were also responsible for substantial proportions of the total numbers of thefts from work (27.3\%), vandalism (23.5\%), and fraud (19.3\%). On balance, it seems more likely that Moffitt's (1993) original typology was incomplete because of age constraints, rather than because sexual offenders are distinct from other offenders in their general offending patterns.

\section{Understanding the Four Sexual Offending Trajectories}

We first compare our work to the two other recent studies which examined sexual offending trajectories over the life course, and then discuss our own results. Lussier and Davies (2011) examined sexual offending up to age 35, and found two offending trajectories: a very low-rate group and a late-onset group which increases in frequency over age. The very low-rate group in this study has 6-year Poisson rates for the three age groups of $0.10,0.07$, and 0.11 showing no increase by age and little or no sex offending over the 18 years of the study. The late-onset increasing group had a mean rate of zero in the first age group (age 18-23) which increases to 2.11 in the middle age group, and then to 6.78 in the final 6-year group. It is hard to reconcile Lussier and Davies's group with our work, but their late-onset increasing group seems to match our high-rate accelerator group, and their very low-rate offending group matches our late-onset accelerator group (as the very low-rate group of Lussier and Davies will commit a sexual offense after age 35, and our late-onset accelerator group starts offending on average around age 28 ).

Freiburger et al. (2012) used a different method for their sample of 500 sex offenders in Virginia. Instead of using the counts of the number of offenses, a set of binary sexual offense indicators was constructed for each year of age between 19 and 33 . The indicators simply measured whether or not there had been one or more sexual offense arrests at that age. A group-based trajectory logit analysis was then carried out on these binary items, using cubic curves to represent the age effect. There was no insistence that the target sexual offense arrest needed to fall between the ages of 19 and 33 .

Freiburger et al. (2012) found three trajectory groups of sexual offending. Their method of analysis meant that the groups needed to be defined in terms of the probability 
of one of more sex offense arrests in a year. The largest group (G3) consisting of two thirds of the sample had a steadily rising probability from 0 at age 23 to 0.2 to age 29 , followed by a decline to zero at age 33 . A second group ( $18 \%$ of the sample) had zero probability up to age 23 , then peaked at age 25 with probability 0.4 , before declining to zero again at age 28 . The third group (14\% of the sample) had a probability at 0 up to age 30 , rising to a probability of around 0.5 at age 32 . This method of analysis makes it hard to reconcile the trajectories with ours, but their study does show evidence of a late-onset group with arrests only after age 30 . The size of this group (at 14\%) is slightly larger than our equivalent late-onset accelerator group (8\%).

Compared to the two groups of Lussier and Davies (2011), and the three groups of Freiburger et al. (2012) our present results yield four groups when the sexual offending over the whole life course was considered. Most importantly, in the specific sample of those referred to a treatment clinic, we found that all trajectories persisted into middle age. Close to a quarter of sexual offenders belonged to Group 2, who desisted by their late $40 \mathrm{~s}$ (high-rate limiteds), but the three other sexual trajectory groups persisted into their late $50 \mathrm{~s}$. One of these - the low-rate persistents - were over half of the sample and were offenders who started sexual offending in their teens and persisted at a steady rate of about one sexual offense a year up to age 58 . They were equally likely to commit rape as child molestation. We also found two late bloomer trajectory groups who started offending later, but who persisted into their late 50s. Both of these groups were unlikely to be involved in rape, instead focusing their sexual offending on children.

There is little scope from the variables analyzed to explain why there is such a range in referral status across groups. Essentially, the majority of the early-onset groups were committed for treatment and most of the later onset groups were observed (not committed) and released. The results are reassuring in that the analysis corroborates to some degree that the professionals at the MTC recognized genuine differences among the groups with respect to the need for extended confinement and the potential value of treatment.

From the perspective of the MTC, one can say with some confidence that during the period of referral under study, they received three groups of men for assessment: (a) those who were on average in their 20s (low-rate persistent, high-rate limiteds, highrate accelerators; Groups 1, 2, \& 3); (b) those who were on average in their 30s (lowrate adult onset; Group 4); and (c) those who were on average in their late 40s (late-onset accelerators; Group 5). As emphasized earlier, although the former three groups (Groups 1, 2, \& 3) have been identified in studies with an age range up to their mid-30s, the remaining groups (Groups $4 \& 5$ ) would be overlooked. This latter point underscores the importance of removing the age constraint in studying sex offenders.

When the relationship between the trajectories for sexual and any offending was examined, additional insight was gained. Essentially, persistent sexual offenders (Groups 3 \& 4) are likely also to be persistent general offenders and thus seem to exhibit criminal versatility throughout their life course. In contrast, high-rate limited sexual offenders are also more likely to be limited in their general offending.

There are limitations to our study. The degree to which any specific study represents a broader population and can therefore be applied to other more general 
situations is an important concern. The present sample is no exception. The offenders in this study represent a fairly unique population and it is not expected that the conclusions drawn from them would generalize to sexual offenders not referred for civil commitment, nonsexual offenders, or even to more contemporary samples of civilly committed sexual offenders. It needs to be remembered that this is a retrospective study of sample defined by their referral to the MTC, and who are therefore sexually offending later in their adult life. Thornberry and Krohn (2005) have recently reminded us of Robin's (1978) paradox: that most antisocial children do not become antisocial adults. Our sample tells us little about juveniles who have sexually offended and their propensity to desist early from sexual offending, and this must be a focus for future work.

A further issue and potential limitation is the use of date of charge and the nature of sex-offending charges. Charges will always postdate the date of offense, and this is a limitation when using date of charge from official sources. Additionally, some offenses such as incest may take place over a period of years and the date of charge may not truly represent the range of dates when the offenses took place. In addition, some offenders may escape detection for long periods of time and their prior offenses when charged and detected will be clumped together with the same charge date. Aggregation of counts into 5-year periods alleviates this last problem to some degree, as does the use of a trajectory distribution (the negative binomial) that accounts for such overdispersion.

Nevertheless, this study still contributes to the field in a number of ways. Given that such a compelling majority of offenses are so often attributed to a disproportionately small number of offenders, it makes sense to study those chronic, persistent offenders in more detail (DeLisi, 2001). One advantage of concentrating on only the most serious criminals is that no one can dispute the gravity of their offenses (Soothill \& Gibbens, 1978). Further, because so much of criminological research has come from studies of largely trivial offending and general delinquency, a sound empirical understanding of more serious offenses is clearly necessary (DeLisi, 2001).

This study has identified that there are distinct trajectories for sexual offending. This finding emerged from a comparatively restricted series of cases that were referred to the MTC on the basis that they needed treatment or were considered potentially sexually dangerous. If such distinctions become evident among cases referred for potential commitment at a facility that one might expect would draw similarly profiled cases then it is reasonable to hypothesize that there will be distinct trajectories for sexual offending within the general population. The groups identified in this study will be among these, but there may well be other groups of sex offenders who might never be considered appropriate for civil commitment. Regardless, one point appears clear; it is inappropriate to consider sex offenders to be a homogeneous group.

From these rather specific developments in relation to sexual offending, there has also been an attempt to link analyses of sexual offending into the mainstream of criminal careers research. To achieve this we return to our starting-point. Tracing a lineage from Moffitt's pioneering work; our present study shows the similarities and differences of the general offending patterns among predominantly sexual offenders compared with the general population of offenders. For example, earlier we pointed to 
the similarities between our offender groups and Moffitt's iconic groups (adolescentlimiteds and life course persistents) as well as the groups that have emerged in the works of Lussier and his colleagues.

\section{Declaration of Conflicting Interests}

The authors declared no potential conflicts of interest with respect to the research, authorship, and/or publication of this article.

\section{Funding}

The authors received no financial support for the research, authorship, and/or publication of this article.

\section{Notes}

1. Murder, rape, child molestation, assault, other contact sexual offenses, noncontact sexual offenses, dangerous or negligent acts occasioning bodily harm (including drunk driving), abduction, robbery, burglary, breaking and entering, theft (including auto theft), white collar crime, other property offenses, weapons, drug-related offenses, alcohol-related offenses (not drunk driving), public order, military/justice related infractions, motor vehicle violations (not auto theft), and miscellaneous offenses.

2. The two criteria are defined as $\mathrm{BIC}=-2 \log (\mathrm{L})+\log (\mathrm{N}) \cdot \mathrm{K}$, and $\mathrm{AIC} 3=2 \log (\mathrm{L})+3 \mathrm{~K}$, where $N$ is the sample size, $\mathrm{L}$ is the likelihood of the model, and $\mathrm{K}$ is the number of parameters. The AIC3 therefore imposes a less stringent penalty on the analysis than does BIC for most analyses.

\section{References}

Alexander, M. A. (1999). Sexual offender treatment efficacy revisited. Sexual Abuse: A Journal of Research and Treatment, 11(2), 101-117.

Brame, R., Nagin, D. S., \& Wasserman, L. (2006). Exploring some analytic characteristics of finite mixture models Journal of Quantitative Criminology, 22, 31-59.

Bushway, S., Thornberry, T. P., \& Krohn, M. D. (2003). Desistance as a developmental process: A comparison of static and dynamic approaches. Journal of Quantitative Criminology, 19, 129-153.

Collins, L. M., \& Lanza, S. T. (2010). Latent class and latent transition analysis: With applications in the social, behavioral, and health sciences. New York, NY: Wiley.

DeLisi, M. (2001). Extreme career criminals. American Journal of Criminal Justice, 25, 239-252.

Dias, J. (2006). Latent class analysis and model selection. In M. Spiliopoulou, R. Kruse, C. Borgelt, A. Nürnberger, \& W. Gaul (Eds.), From data and information analysis to knowledge engineering (pp. 95-102). New York, NY: Springer.

Eggleston, E., \& Laub, J. (2002). The onset of adult offending: A neglected dimension of the criminal career. Journal of Criminal Justice, 30, 603-622.

Ewing, C. P. (2011). Justice perverted: Sex offender law, psychology, and public policy. New York, NY: Oxford University Press.

Farrington, D., Coid, J., Harnett, L., Jolliffe, D., Soteriou, N., Turner, R., \& West, D. (2006). Criminal careers up to age 50 and life success up to age 48: New findings from the Cambridge study in delinquent development. (2nd ed., Home Office Research Study 299). 
London, UK: Home Office. Retrieved from http://www.homeoffice.gov.uk/rds/pdfs06/ hors299.pdf

Francis, B., Hargreaves, C., \& Soothill, K. (2014). Changing prevalence of sex offender convictions-disentangling age, period and cohort effects over time. In A. Blokland \& P. Lussier (Eds.), Sex offenders: A criminal career approach. New York, NY: Wiley.

Freiburger, T., Marcum, C., Iannacchione, B., \& Higgins, G. (2012). Sex offenders and criminal recidivism: An exploratory trajectory analysis using a Virginia sample. Journal of Crime and Justice, 35, 365-375

Hanson, R. K. (2002). Recidivism and age: Follow-up data from 4,673 sexual offenders. Journal of Interpersonal Violence, 17, 1046-1062.

Hanson, R. K., Bourgon, G., Helmus, L., \& Hodgson, S. (2009). The principles of effective correctional treatment also apply to sexual offenders: A meta-analysis. Criminal Justice and Behavior, 36, 865-891.

Harris, D. A. (2008). Offense specialization and versatility in men convicted of sexual offenses and referred for civil commitment. Unpublished doctoral dissertation, Griffith University, Queensland, Australia.

Harris, D. A., Mazerolle, P., \& Knight, R. A. (2009a). Understanding male sexual offending: A comparison of general and specialist theories. Criminal Justice and Behavior, 36, 1051-1069.

Harris, D. A., Smallbone, S., Dennison, S., \& Knight, R. A. (2009b). Specialization and versatility in sexual offenders referred for civil commitment. Journal of Criminal Justice, 37, 37-44.

Jennings, W., Zgoba, K., \& Tewksbury, R. (2012). A comparative longitudinal analysis of recidivism trajectories and collateral consequences for sex and nonsex offenders released since the implementation of sex offender registration and community notification, Journal of Crime and Justice, 35, 356-364

Knight, R. A., \& Thornton, D. (2007). Evaluating and improving risk assessment schemes for sexual recidivism: A long-term follow-up of convicted sexual offenders. (Final Report, NCJ 217618). Retrieved from http://nij.ncjrs.gov/publications.

Laws, R., \& Ward, T. (2011). Desistance from sex offending: Alternatives to throwing away the keys. New York, NY: The Guilford Press.

Lieb, R., Quinsey, V., \& Berliner, L. (1998). Sexual predators and social policy. Crime and Justice, 23, 43-114.

Lösel, F., \& Schmucker, M. (2005). The effectiveness of treatment for sexual offenders: A comprehensive meta-analysis. Journal of Experimental Criminology, 1, 117-146.

Lussier, P. (2005). The criminal activity of sexual offenders in adulthood: Revisiting the specialization debate. Sexual Abuse: A Journal of Research and Treatment, 17, 269-292.

Lussier, P., \& Davies, G. (2011). A person-oriented perspective on sexual offenders, offending trajectories, and risk of recidivism: A new challenge for policymakers, risk assessors, and actuarial prediction? Psychology, Public Policy, and Law, 17, 530-561.

Lussier, P., Tzoumakis, S., Cale, J., \& Amirault, J. (2010). Criminal trajectories of adult sexual aggressors and the prediction of reoffending: Examining the aging-effect. International Criminal Justice Review, 20, 147-168.

McGee, T. R., \& Farrington, D. P. (2010). Are there any true adult-onset offenders? British Journal of Criminology, 50, 530-549.

McGloin, J. M., Sullivan, C. J., \& Piquero, A. R. (2009). Aggregating to versatility? Transitions among offender types in the short-term. British Journal of Criminology, 49, 243-264. 
Miethe, T., Olson, J., \& Mitchell, O. (2006). Specialization and persistence in the arrest histories of sex offenders: A comparative analysis of alternative measures and offense types. Journal of Research in Crime and Delinquency, 43, 204-229.

Moffitt, T. E. (1993). "Life course persistent" and "adolescence-limited" antisocial behavior: A developmental taxonomy. Psychological Review, 100, 674-701.

Nagin, D. S., \& Odgers, C. L. (2010) Group-based trajectory modeling in clinical research. Annual Review of Clinical Psychology, 6, 109-138.

Nagin, D. S. (2005). Group-based modeling of development. Cambridge, MA: Harvard University Press.

Sampson, R. J., \& Laub, J. H. (1993). Crime in the making: Pathways and turning points through life. Cambridge, UK: Harvard University Press.

Sampson, R. J., \& Laub, J. H. (2003). Life course desisters? Trajectories of crime among delinquent boys followed to age 70. Criminology, 41, 555-591.

Simon, L. (1997). Do criminal offenders specialize in crime types? Applied and Preventive Psychology, 6, 35-53.

Smallbone, S., Marshall, W., \& Wortley, R. (2008). Preventing child sexual abuse: Evidence, policy and practice. Cullompton, UK: Willan Publishing.

Soothill, K. (2010). Sex offender recidivism. In M. Tonry (Ed.), Crime and justice. A review of research (Vol. 39., pp. 145-211). Chicago, IL: University of Chicago Press.

Soothill, K., Francis, B., Sanderson, B., \& Ackerley, E. (2000). Sex offenders-Specialists, generalists or both? British Journal of Criminology, 40(1), 56-67.

Soothill, K., \& Gibbens, T. (1978). Recidivism of sexual offenders: A Re-Appraisal. British Journal of Criminology, 18, 267-276.

Sullivan, C. J., McGloin, J. M., Pratt, T. C, \& Piquero, A. R. (2006). Rethinking the "norm" of offender generality: Investigating specialization in the short-term. Criminology, 44, 199-233.

Tewksbury, R., \& Jennings, W. G. (2010). Assessing the impact of sex offender registration and community notification on sex-offending trajectories. Criminal Justice and Behavior, $37,570-582$.

Tewksbury, R., Jennings, W. G., \& Zgoba, K. M. (2012). A longitudinal examination of sex offender recidivism prior to and following the implementation of SORN. Behavioral Sciences and the Law, 30, 308-328.

Thornberry, T. P., \& Krohn, M. D. (2005). Applying interactional theory to the explanation of continuity and change in antisocial behaviour. In D. P. Farrington (Ed.), Integrated developmental and life course theories of offending (pp. 183-209). New Brunswick, NJ: Transaction Publishers.

Vermunt, J. K., \& Magidson, J. (2005). Latent GOLD 4.0 user's guide. Belmont, MA: Statistical Innovations Inc.

Weinrott, M., \& Saylor, M. (1991). Self-report of crimes committed by sex offenders. Journal of Interpersonal Violence, 6, 286-300.

Williams, R., \& Arnold, B. (2002). Offense specialization among serious habitual juvenile offenders in a Canadian city during the early stages of criminal careers. International Criminal Justice Review, 12, 1-21.

Willis, G., Levenson, J., \& Ward, T. (2010). Desistance and attitudes towards sex offenders: Facilitation or hindrance? Journal of Family Violence, 25, 545-556.

Zimring, F., Piquero, A., \& Jennings, W. (2007). Sexual delinquency in Racine: Does early sex offending predict later sex offending in youth and young adulthood? Criminology and Public Policy, 6, 507-534. 